\title{
Nurse Midwives Knowledge Regarding Nursing Management of Post-Partum Hemorrhage at in Iraq
}

\author{
Hanan Noor Mohammad \\ ${ }^{1}$ Assist. Lecturer, College of Nursing. University of Altoosi, Najaf City, Iraq
}

\begin{abstract}
Aims: Today, it is well-known that postpartum hemorrhage (PPH) is the leading cause of maternal postpartum deaths worldwide; so that this study aims to assess nurses and midwives knowledge .

Method: A descriptive cross-sectional study design was conducted from to meet the previously mentioned objectives . All nurse midwives $(\mathrm{n}=150)$ were included who works at the hospital of AL-Najaf AL-Ashraf Province .A constructed questionnaire was prepared and adopted by the researcher to meet the objectives of the study.

Results: The result of the study revealed that the mean overall knowledge score of the study participants for all domains was (1.91) which indicated that the overall knowledge of nurse-midwives in Al- Najaf ALAshraf city in Iraq hospitals regarding nursing care of PPH was (fair) the overall knowledge score about prevention of PPH was (1.87) which is also considered (fair) . The result of the current study also revealed that there is a significant positive correlation had been found between age, duration of experience in delivery room, training courses or workshops

Conclusion: It was concluded that the nurse-midwives have a moderate level of knowledge about the overall concepts, information and skills related to the PPH . They have weak knowledge about definition, types and common causes of postpartum hemorrhage .
\end{abstract}

Keywords: Nurse-midwives, knowledge, postpartum hemorrhage, management.

\section{Introduction}

Postpartum hemorrhage $[\mathrm{PPH}]$ is being designated as the most substantial yet inevitable source of death and maternal illness all over the world ${ }^{[1]}$. Being the utmost prevailing 5th maternal mortality cause, $\mathrm{PPH}$ instigate 140,000 demises each year worldwide ${ }^{[2]}$. Rendering the WHO, the distinct $\mathrm{PPH}$ definition is being stated by way of $500 \mathrm{ml}$ minimum blood loss after childbirth within 24 hours. However, the severe PPH is termed as $1000 \mathrm{ml}$ least blood loss in 24 hours of birth [3]. Another definition is that PPH the sufficient loss of blood causing hypovolemia, a [10\%] decrease in the hematocrit or a situation necessitating the transfusion of blood products irrespective of the delivery route [1]. PPH has been categorized into two types: primary and secondary PPH ${ }^{[1]}$. Primary [immediate] PPH is typified by a blood loss of more than $500 \mathrm{ml}$ owning to vaginal delivery and blood loss of $1500 \mathrm{ml}$ owning to caesarean section within first 24 hrs of delivery ${ }^{[2]}$. Practically uterine atony is considered to be the root of $70 \%$ of immediate $\mathrm{PPH}$. Inadequate contraction of the uterus after a child is born referred to as atony of the uterus. The prevalence of immediate PPH is [5\%] of all deliveries ${ }^{[4]}$. An approximated 14 million cases of $\mathrm{PPH}$ are registered every year globally with a [1\%] casefatality rate ${ }^{[5]}$. According to an assessment, about $2 \%$ of the women childbirths are associated to PPH. Although, another approximation indicates the ratio of $25 \%$ global maternal deaths while marking the $\mathrm{PPH}$ as a widely held prime reason of demise in low wages countries. Economically well developed countries has overall less decease risk than the developing nations. In the highincome countries, the total death risk is approximated to be 1:100,000 deliveries as compared to 1:1000 in lowincome countries. ${ }^{[3]}$ According to Rath [2011], a recent WHO analysis showed that in high-income countries, 
hemorrhage as a result of PPH accounts for [13.4\%] of maternal mortality,[30.8\%] for Asia, and 34\% for Africa $^{[5]}$. With a broad difference globally, the incidence of minor PPH and severe PPH is estimated to be [6\%] and $[1.86 \%]$ of all deliveries ${ }^{[4,5]}$. Morbidity resulting from severe $\mathrm{PPH}$ is approximated at 4.5-6.7/1000 deliveries with nearly 20 million women globally every year suffering from an acute or chronic disability due to $\mathrm{PPH}^{[6-8]}$.

\section{Methodology}

2.1 Study aims: The purpose of the current study was to investigate the nurse midwives knowledge regarding nursing care of PPH. The current study also aims to find out the relationship between nurse midwives knowledge regarding nursing care of post- partum hemorrhage with their socio demo-graphic and personal characteristics such as (age, marital status,economic status, educational level, ect......).

2.2 Design of the study: A descriptive crosssectional study design was conducted from 30/July/2019 to $29 /$ April/2020 to meet the previously mentioned objectives

2.3 Study Sample: All nurse midwives $(n=150)$ were included who works at the hospital of AL-Najaf AL-Ashraf city in Iraq

2.4 Study instrument: A constructed questionnaire was prepared and modified after a thorough review of the relevant literature. This questionnaire covers two parts:

2.4.1 Part 1: Socio- demographic and personal characteristics: This part included the following (age, level of education, duration of experience in delivery room, receiving training courses or workshop about postpartum hemorrhage, accommodation, type of accommodation, marital status, economic status, others) which included (8) items.

2.4.2 Part 2: Knowledge of nurse midwives about prevention of postpartum hemorrhage which included (18)items.

2.5 Validity and Reliability: The content validity of the instrument was established through a panel of (12) experts, the reliability of the items was based on the internal consistency of the checklist was assessed by calculating Cronbach Alpha which was $=0.765$
2.6. Data Collection and Data Analysis: A structured questionnaire used to collect data by direct interview. The approximate interview time of 25-30 minutes was provided for the questionnaire completion. To determine whether the objectives of the study were met, the current study data were analyzed by using SPSS, version 25.

\section{Results and Discussion}

Table 1., illustrates the demographic characteristics of the 150 nurse-midwives who participated in this study. Age distribution of the participants revealed that the highest percentage is $67(44.7 \%)$ aged $20-29$ years . Concerning the level of education, highest percentage is $111 / 150$ (74\%) nurse-midwives had secondary school of nurse-midwifery level . Regarding accommodation, findings also revealed that 88 nurse-midwives (58.7\%) were living close to the health institution, and 62 (41.3\%) were living far from the health institution. For, the type of accommodation, owned documented by 79 (52.7\%) nurse-midwives and rented by $71(47.3 \%)$. The enough economic status reported by 20 nurse-midwives (13.3\%) enough to some limits in $58(38.7 \%)$ and not enough in 72 nurse-midwives (48\%). Out of the 150 nursemidwives, 119 (79.3\%) were married, 24 (16\%) were single and 7 nurse-midwives $(4.7 \%)$ were widowed, divorced or separated.

According to the results of the current study, the research outcomes specified age distribution of the respondents while revealing that the highest age group is between $(20-29)$ years which made up $(44.7 \%)$, secondary was age category (30-39) years which constituted $(22 \%)$. These data may vary from that gotten by (40) who observed that the highest age group is (47$55)$ years $(32.5 \%)$, followed by $(20-28)$ years $(24.7 \%)$. The results of the present study indicate the target sample; it also indicated that young nurses midwives made up the majority among the other groups .

Regarding the educational level, the majority of the study group (74\%) are graduated in secondary school of midwifery, this may be due to secondary school of midwifery are the major levels that qualify health care workers in the range of midwifery, principally in Iraq . One previous study achieved in the city of Maraco found that the majority midwives $(35.1 \%)$ that were included in the current study graduated from secondary schools (9). In relation to residence, results also explained that 88.0 nurse-midwives (58.7\%) are living near the health 
institutions, and $62(41.3 \%)$ are living away from the health institutions .

Concerning the socio-economic status, most of the research respondents (48\%) have not sufficient monthly income. This result can be supported by other results about the accommodation which recorded that (47\%) of the midwives have rent accommodation ${ }^{(12)}$.

Regarding to marital status, most of the study sample $(79.3 \%)$ are married, while (16\%) are single and $(4.7 \%)$ are widowed, divorced or separated as shown in (Table 1).

Table 1. Demographic Characteristics of the Studied Group

\begin{tabular}{|c|c|c|c|}
\hline Variable & Category & $(\mathrm{N}=150)$ & $\%$ \\
\hline \multirow{5}{*}{ Age (year) } & Less than 20 & 18 & 12.0 \\
\hline & $20-29$ & 67 & 44.7 \\
\hline & $30-39$ & 33 & 22.0 \\
\hline & $40-49$ & 23 & 15.3 \\
\hline & 50 and above & 9 & 6.0 \\
\hline \multirow{6}{*}{ Level of Education } & Nursing school & 12 & 8.0 \\
\hline & Secondary school of midwifery & 111 & 74.0 \\
\hline & Secondary school of Nursing & 17 & 11.3 \\
\hline & Institute of nursing & 8 & 5.4 \\
\hline & Institute of midwifery & 2 & 1.3 \\
\hline & College of nursing & 0 & 0.0 \\
\hline \multirow{2}{*}{ Accommodation } & Close to the health institution & 88 & 58.7 \\
\hline & Far from the health institution & 62 & 41.3 \\
\hline \multirow{2}{*}{ Type of Accommodation } & Owned & 79 & 52.7 \\
\hline & Rented & 71 & 47.3 \\
\hline \multirow{3}{*}{ Economic Status } & Enough & 20 & 13.3 \\
\hline & Enough to some limits & 58 & 38.7 \\
\hline & Not enough & 72 & 48.0 \\
\hline
\end{tabular}

According to the table 2, the distribution of duration of experience in delivery room together with history of training about postpartum hemorrhage was illustrated, where 20 participants $(13.3 \%)$ had a duration of experience in delivery room for less than one year, 73 (48.7\%) had a duration of one to ten years, $31(20.7 \%)$ for $11-20$ years, 18 (12\%) for 21-30 years and 8 nursemidwives $(5.4 \%)$ had a duration of experience in delivery room of more than 30 years. Regarding the training about postpartum hemorrhage, 109 nurse-midwives $(40 \%)$ had received training courses, 90 (33.1\%) had participated in workshops and 73 (26.8\%) nurse-midwives received other types of training.
Table 3., demonstrated the responses of nursemidwives about management of $\mathrm{PPH}$; it points that 43.0 respondents (28.7\%) had the correct response concerning the assessment of blood loss directly by kidney dish, $72.0(48 \%)$ of respondents have incorrect response and $35.0(23.3 \%)$ they don't know. The MS was 1.81 and it was a moderate knowledge.

Pads count and weight were correctly identified to be included in the management and assessment of PPH by 65.0 of respondents (43.3\%), 44.0 (29.3\%) of respondents were incorrect and $41.0(27.3 \%)$ of them did not know. This gave a mean score of 2.14 which is moderate knowledge. 
Regarding the responses about recording the vital signs, correct responses reported by 69.0 respondents (46\%), incorrect answers by $46.0(30.7 \%)$ and 35.0 $(23.3 \%)$ did not know with a mean score of 2.15 and it was moderate knowledge. About $36.0(42 \%)$ respondents correctly answered and forty sex (30.7\%) incorrectly responded about measurement of pulse and other vital signs every 15 minutes up to stability but 41.0 (27.3\%) of respondents do not know. The mean score was 2.11 and it was moderate knowledge. Correct response regarding management of call for help observed by 74.0 respondents (49.3\%), incorrect answers were reported by
$34.0(22.7 \%)$ and $42.0(28 \%)$ respondents do not know. This gave a mean knowledge score of 2.27 and moderate knowledge. Some other data about this domain are different; Elfaki (2015) observed that nurses-midwives» knowledge about method of assessment of blood loss are $(26 \%),(66.2)$ and $(28.6 \% 0)$ respectively for (pads count and weight), (assess of blood loss directly by kidney dish) and (observe vital signs) ${ }^{(9)}$; while Faiza (2015) found the following correct responses : (77.6\%), $(53.1 \%)$ and $(65.5 \%)$ respectively for pads count and weight), (assess of blood loss directly by kidney dish) and (observe vital signs) $)^{(10)}$.

Table 2. Distribution of Duration of Experience in Delivery Training about Postpartum Hemorrhage

\begin{tabular}{|c|c|c|c|}
\hline Variable & Category & No. & $\%$ \\
\hline \multirow{6}{*}{ Duration of Experience in Delivery Room } & $<1$ year & 20 & 13.3 \\
\hline & $1-10$ & 73 & 48.7 \\
\hline & $11-20$ & 31 & 20.7 \\
\hline & $21-30$ & 18 & 12.0 \\
\hline & $>30$ & 8 & 5.3 \\
\hline & Total & 150 & 100.0 \\
\hline \multirow{4}{*}{ Receiving Training about Postpartum Hemorrhage } & Training course & 109 & 40.1 \\
\hline & Workshop & 90 & 33.1 \\
\hline & Other training & 73 & 26.8 \\
\hline & Total & $272 *$ & 100.0 \\
\hline
\end{tabular}

*Nurse-Midwives Mentioned more than One Choice

Concerning management, good knowledge was gotten by Faiza (2015) for all the questions of the management of PPH . Mohammed et al. (2016) conducted a study in Nigeria showed that about $67.1 \%$ of the nurses and midwives have correct answers about using massage as initial step to manage $\mathrm{PPH}^{(10)}$; Onasoga et al. (2012) achieved another study in Nigeria observed that $95 \%$ of midwives had correctly answered the question about using uterine massage after labor to prevent the development of $\mathrm{PPH}{ }^{(11)}$.

Table 3. Knowledge of Nurse- Midwives about Management of PPH (N =150)

\begin{tabular}{|c|c|c|c|c|c|c|c|c|c|}
\hline \multirow{2}{*}{ No. } & \multirow{2}{*}{ Items } & \multicolumn{2}{|c|}{ Correct } & \multicolumn{2}{|c|}{ Incorrect } & \multicolumn{2}{|c|}{ Don't know } & \multirow{2}{*}{ MS } & \multirow{2}{*}{ Assessment. } \\
\hline & & Freq. & Percent. & Freq. & Percent. & Freq. & Percent. & & \\
\hline 1 & $\begin{array}{l}\text { Assess of Blood loss Directly by } \\
\text { Kidney Dish }\end{array}$ & 43 & $28.7 \%$ & 72 & $48.0 \%$ & 35 & $23.3 \%$ & 1.81 & Moderate \\
\hline 2 & Pads Countand Weight & 65 & $43.3 \%$ & 44 & $29.3 \%$ & 41 & $27.3 \%$ & 2.14 & Moderate \\
\hline 3 & Observe Vital Signs & 69 & $46.0 \%$ & 46 & $30.7 \%$ & 35 & $23.3 \%$ & 2.15 & Moderate \\
\hline 4 & $\begin{array}{l}\text { Measure the Pulse and other Vital } \\
\text { Signs every } 15 \text { minutes up to Stability }\end{array}$ & 63 & $42.0 \%$ & 46 & $30.7 \%$ & 41 & $27.3 \%$ & 2.11 & Moderate \\
\hline 5 & Management of Call for Help & 74 & $49.3 \%$ & 34 & $22.7 \%$ & 42 & $28.0 \%$ & 2.27 & Moderate \\
\hline
\end{tabular}




\begin{tabular}{|c|l|c|c|c|c|c|c|c|c|}
\hline \multirow{2}{*}{ No. } & \multirow{2}{*}{ Items } & \multicolumn{2}{|c|}{ Correct } & \multicolumn{2}{c|}{ Incorrect } & \multicolumn{2}{c|}{ Don't know } & \multirow{2}{*}{ MS } & Assessment. \\
\cline { 2 - 8 } & Freq. & Percent. & Freq. & Percent. & Freq. & Percent. & & \\
\hline 6 & $\begin{array}{l}\text { Try to Control the Bleeding by } \\
\text { Massage }\end{array}$ & 61 & $40.7 \%$ & 37 & $24.7 \%$ & 52 & $34.7 \%$ & 2.16 & Moderate \\
\hline 7 & Giving I.V Fluid & 84 & $56.0 \%$ & 17 & $11.3 \%$ & 49 & $32.7 \%$ & 2.45 & Good \\
\hline 8 & $\begin{array}{l}\text { Follow up Continue even Bleeding } \\
\text { has Stopped }\end{array}$ & 50 & $33.3 \%$ & 41 & $27.3 \%$ & 59 & $39.3 \%$ & 2.06 & Moderate \\
\hline 9 & Observed Amount of Blood & 77 & $51.3 \%$ & 9 & $6.0 \%$ & 64 & $42.7 \%$ & 2.45 & Good \\
\hline 10 & $\begin{array}{l}\text { Mother Should remain in the labor } \\
\text { Room until Become Stable }\end{array}$ & 86 & $57.3 \%$ & 11 & $7.3 \%$ & 53 & $35.3 \%$ & 2.50 & Good \\
\hline 11 & Overall Knowledge Score & & & & & & 2.21 & Moderate \\
\hline
\end{tabular}

Table 4, shows Spearman's bivariate correlation analysis. A significant direct (positive) correlation had been found between age of participants and their overall knowledge score $(\mathrm{R}=0.412$, $\mathrm{p}$. value $=0.004)$. Other significant direct (positive) correlation was found with duration of experience in delivery room $(\mathrm{R}=0.575, \mathrm{P}$. value $=0.001)$. Moreover, a significant direct (positive) correlation was found with receiving training courses or workshops $(R=0.243, P$. value $=0.043)$. No significant association had been found between overall knowledge scores and other variables including level of education, accommodation, type of accommodation and economic status, (in all of these variables correlation was not significant, $\mathrm{P}$. value $=.05$ ).

Age concerns designated a great substantial positive correlation $(p=.004)$ amid age \& overall knowledge. It means that knowledge and awareness increases with age, this result is in agreement with Jaber and Abbas (2012) who found a significant association $(\mathrm{p}=0.02)$ between midwives' age and their knowledge ${ }^{[14]}$. This may be due to increased practice and experience by increasing age resulting in accumulation of information so that the same table (4.17) shows a high significant positive correlation $(p-=0.001)$ between overall knowledge and duration of experience in delivery room; this result agrees with that obtained by Bulndi et al. (2017) who observed that high levels of knowledge about PPH is found in midwives with years of experience more than 15 years $^{[13]}$.
Unexpectedly, this results did not reveal any significant relationship $(\mathrm{p}=0.495)$ between overall knowledge of nurse-midwives and their level of education, this result agrees with the result obtained by Onasoga et al. ${ }^{[11]}$. However, disagrees with the study conducted by Jaber and Abbas (2012) who pointed a significant relationship with educational status [14]; another study found that doctors have better scores than midwives ${ }^{[15]}$. The unexpected result in the present study may be explained by what is mentioned in this chapter that most of the study sample (74\%) are graduated from secondary school of midwifery, so that there is no great difference in the level of education of respondents participated in this study .

Concerning training, the current study found a significant correlation $(p=0.043)$ between overall knowledge of nurse-midwives and receiving training courses or workshops, this result agrees with the work obtained by Benedict et al. who found that midwives who completed the training courses named "Essential Steps in the Management of Obstetric Emergencies" ESMOE had better knowledge and performance ${ }^{[15]}$. However, another study conducted in Baghdad did not find a significant correspondence of about $p>0.05$ amongst the training and inclusive understanding of nurse midwives ${ }^{[14]}$. 
Table 4. Results of Bivariate Spearman's Correlation Analysis for the Correlation between Overall Knowledge of Nurse-Midwives and Demographic Variables

\begin{tabular}{|l|c|c|}
\hline \multirow{2}{*}{ Socio-Demographic Characteristics } & \multicolumn{2}{|c|}{ Overall mean knowledge score } \\
\cline { 2 - 3 } & Spearman's correlation coefficient & P. value \\
\hline Age (year) & 0.412 & 0.004 \\
\hline Level of Education & 0.056 & 0.495 \\
\hline Accommodation & 0.044 & 0.595 \\
\hline Type of Accommodation & 0.028 & 0.738 \\
\hline Economic Status & 0.145 & 0.076 \\
\hline Marital Status & 0.154 & 0.060 \\
\hline Duration of Experience in Delivery Room & 0.575 & 0.001 \\
\hline Receiving Training Courses or Workshops & 0.234 & 0.043 \\
\hline
\end{tabular}

\section{Conclusion}

According to the current study, the nurse-midwives have a moderate level of knowledge about the overall information and skills related to the management of $\mathrm{PPH}$. In general, the knowledge of nurse-midwives about PPH increases with age and years of experience.

Financial Disclosure: There is no financial disclosure.

Conflict of Interest: None to declare.

Ethical Clearance: All experimental protocols were approved under the College of Nursing and all experiments were carried out in accordance with approved guidelines.

\section{References}

1. Edhi, Muhammad Muzzammil, Aslam, H. M., Naqvi, Z. and Hashmi, H.Post partum hemorrhage: causes and management. BMC research notes, 2013; 6(1) :236-249 .

2. Sheikh, L., Najmi, N., Khalid, U., \& Saleem, T. Evaluation of compliance and outcomes of a management protocol for massive postpartum hemorrhage at a tertiary care hospital in Pakistan. BMC pregnancy and childbirth, 2011; 11(1): 28-45

3. World Health Organization.. WHO recommendations for the prevention and treatment of postpartum haemorrhage. World Health Organization, 2012.
4. Taylor, U. K., Delorme, P., \& Miller, S. FIGO guidelines: prevention and treatment of postpartum hemorrhage in low-resource settings. Inter.1J.1 of Gyn. and Obstet., 2012; 117(1): 108-118.

5. Rath, W. H. Postpartum hemorrhage-update on problems of definitions and diagnosis. Acta obstetricia et gynecologica Scandinavica, 2011; 90(5) : 421-428.

6. Carroli, G., Cuesta, C., Abalos, E., \& Gulmezoglu, A. M.Epidemiology of postpartum haemorrhage: a systematic review. Best practice \& research Clin.1 obstet. \& gyn., 2008; 22(6):999-1012.

7. Winikoff, B., Dabash, R., Durocher, J., Darwish, E., Ngoc, N. T. N., León, W., ... \& Blum, J. Treatment of post-partum haemorrhage with sublingual misoprostol versus oxytocin in women not exposed to oxytocin during labour: a doubleblind, randomised, non-inferiority trial. The Lancet, 2010; 375(9710):210-216.

8. Widmer, M., Blum, J., Hofmeyr, G. J., Carroli, G., Abdel-Aleem, H., Lumbiganon, P., ... \& Mignini, L. E. Misoprostol as an adjunct to standard uterotonics for treatment of post-partum haemorrhage: a multicentre, double-blind randomised trial. The Lancet, 2010; 375(9728) :1808-1813.

9. Elfaki, B. B. M.Assessment of Nurse Midwives' Knowledge Regarding Nursing Care of PostPartum Hemorrhage at Ribat University Hospital and Omdurman Maternity Hospital . Master dissertation, Gezira University, 2015 .

10. Faiza. A.N . Knowledge and Practice of Nurse 
Midwives Regarding Management and Prevention of Postpartum Hemorrhage in Three Selected Teaching Hospitals-Khartoum State-Sudan 2014. Ind J of Appl Res, 2015;5(4): 634-8.

11. Onasoga, O. A., Awhanaa, Akpomeyoma T. and Amiegheme F. E. Assessment of knowledge of strategies used in the prevention and management of postpartum haemorrhage by midwives in Bayelsa State, Nigeria . Arch. Appl. Sc. Res., 20124 (1):447453.

12. Guyton, A. C. and Hall, J. E. Textbook of Medical Physiology . 13th Ed., Elsevier Saunders. Philadelphia, USA, 2016.

13. Bulndi, L. B.; Seljul, R. M.; Ogundeko, O. T.; Pual, B. A.; Godwin, A. O.; Godwin, B. I.; Nanbur, S.; Ubanyi, T. and Mary, R. S. Knowledge and
Management of Post Partum Haemorrhage Among Skilled Birth Attendants in Primary Health Centres of Jos North LGA, Plateau State. Pub. Heal. Inter.., 20172 (4) : 22-39.

14. Jaber, E. A. and Abbas, I. M. Assessment of licensed indigenous midwives' knowledge concerning prevention and management of postpartum hemorrhage in Baghdad city. Iraqi National Journal of Nursing Specialties, 2011;24(2): 1-12 .

15. Benedict, M.; Steinberg, W. J.and Raubenheimer, J. E. Knowledge of The Management of Postpartum Haemorrhage By Doctors and Midwives Working in Free State District Hospitals. Afr. J. Nur. and Mid., 2016;18(2):146-161 . 